\title{
The Effectiveness of Group Cognitive Behavioral Therapy Based on Cash's Eight-Step Model in Body Image of Primiparous Women
}

\author{
Ali Navidian, ${ }^{1}$ Zahra Moudi, ${ }^{1}$ and Mehri Esmaealzade ${ }^{2,}$ \\ ${ }^{1}$ Pregnancy Health Research Center, Zahedan University of Medical Sciences, Zahedan, IR Iran \\ ${ }^{2}$ Zahedan University of Medical Sciences, Zahedan, IR Iran \\ "Corresponding author: Mehri Esmaealzade, MSc Student of Counseling in Midwifery, Zahedan University of Medical Sciences, Zahedan, IR Iran. E-mail: mehri1366@yahoo.com
}

Received 2016 May 24; Revised 2016 October 02; Accepted 2016 October 22.

\begin{abstract}
Background: Prevalence of body image disorder in postpartum period, especially in primiparous women is relatively high. This study aimed to determine the effectiveness of cognitive behavioral group therapy based on the cash's eight-step model in body image of primiparous women.

Objective: This study aimed to determine the effectiveness of cognitive behavioral group therapy based on the cash's eight-step model in body image of primiparous women.

Methods: This research was a pretest-posttest quasi-experimental study in which, 61 primiparous women referring to health centers in Zahedan were selected according to convenience sampling method and randomly assigned into intervention and control groups. The multidimensional body-self relations questionnaire (MBSRQ) was used to collect data. The intervention group received group cognitive behavioral body image therapy based on the Cash model and the control group remained pending. After six weeks, both groups completed the MBSRQ again. Data analysis was performed using descriptive statistics and analysis of covariance in SPSS 22. Results: Analysis of covariance showed that the mean scores on appearance evaluation $(\mathrm{P}=0.0001)$, body areas satisfaction $(\mathrm{P}=$ 0.0001), and the total score of body image $(\mathrm{P}=0.0001)$ in the intervention group were significantly higher than those in the control group. However, in terms of appearance orientation, fitness evaluation, fitness orientation, and subjective weight, there was no significant difference between the two groups $(\mathrm{P}>0.05)$.

Conclusions: Due to the effectiveness of cognitive behavioral therapy based on Cash model in primiparous women's body image, it is recommended to use this method of consultation in health care programs after child birth to improve the women's body image and prevent subsequent psychological problems.
\end{abstract}

Keywords: Body Image, Cognitive Behavioral Therapy, Multidimensional Body-Self Relations, Primiparous Women

\section{Background}

Body image is far beyond the mental image of individuals from the appearance and reflects his/her personal relations with the body and involves conceptions, beliefs, thoughts, emotions, and activities related to the physical appearance (1). This complicated structure includes perceptional, observational, and behavioral components (2). Body image disorder refers to the problems occurred, partially or wholly, in this regard (3). Body image disorder in general population is correlated with the weak psychiatric function, and its relation with depression, social anxiety, low self-esteem, inappropriate sexual performance, and unsafe/preoccupied attachment style has been approved (4). Women are more vulnerable in suffering from depression and anxiety caused by body image disorder (5). 80 percent of women agreed upon observing the others' image through media, fashion magazines and forcing by the peers group, family members and friends that will result in the sense of distrust to their appearance (6).

The individuals' body image can be altered through changes in health status, for example in case of sickness or injuries. This change not only may be seen in conditions such as skin diseases, fatness, burnings, and alopecia, but also it is inevitable in changes arising from puberty, aging, pregnancy, and menstruation period. The most noticeable alterations in pregnancy are gaining weight and body deformation, i.e., growing belly, breasts heaviness and tenderness, skin changes such as chloasma, spider telangiectasia, varicose veins, and stretch marks (7). Being concerned about continuation of inappropriate pregnancy changes after delivery is one of the most important concerns among pregnant women (6).

Meantime, primiparous mothers who are faced with many changes in their body during the first pregnancy and after delivery are less satisfied with their body image and its consequences. Indeed, they may feel shamefacedly due to inability to maintain their initial weight and fitness (8). Negative maternal body image can result in depression and eating disorder and also influence their child's eating behaviors (8). Mothers with more body satisfaction are

Copyright (c) 2016, Mazandaran University of Medical Sciences. This is an open-access article distributed under the terms of the Creative Commons 
more interested in breastfeeding their infants and show more attachment behaviors to their child. On the other hand, there is a relationship between body dissatisfaction after delivery and psychiatric depression (9). Several studies have confirmed the mothers' body image disorder after delivery in comparison with pre-pregnancy period and even during pregnancy (8-14); therefore, treatment of body image disorders is an increasingly considerable issue (2, 15).

Many different methods including exercise (16), cosmetic surgery (17), dance therapy (18), life style therapy (19), group existential and reality therapy (20), and a variety of cognitive behavioral therapies (21-26) have been proposed to cope with body image dissatisfaction. It seems that cognitive behavioral therapies are the most effective treatment methods in body image dissatisfaction (21). Such evidence-based approach, strategies, and techniques have been combined with scientific findings related to this special disorder (3) and by changing individual's maladaptive cognitions, which are responsible for negative automatic thoughts, an improvement in emotional distress and problematic behaviors can be occurred (22). In general, cognitive behavioral therapy for body image disorder includes psycho-education, self-monitoring, cognitive reconstructing, exposure and response prevention, desensitization, and training precise estimation of body size (3). Thomas F.Cash has presented the cognitive behavioral body image therapy as an eight-step model and carried out studies to evaluate its effectiveness (27-29). Cash has applied this model to treat body image disorder in two groups of individuals and could help improve subsequent problems such as eating disorder, depression, and body dimorphic disorder (1).

The results of studies by Rozen et al. (1995 and 1989) indicate the effectiveness of cognitive behavioral therapy in the body image of women with normal weight and negative body image among obese women $(23,24)$. Rayegan et al. (2008) emphasized the impact of cognitive behavioral therapy based on Cash's model on negative body image among girl students (26) Fadaei et al. (2011) found out that cognitive behavioral therapy is effective in body image of women under mastectomy (25). On the other hand, the results of Nicolino study did not indicate the effectiveness of short cognitive behavioral therapy in the body image of college women (21). Similar researches have been conducted by Hutchinson (30), Dworkin et al. (31), Philips et al. (32), Hilbert (33), Wilhelm et al. (34), Azari et al. (35), Rahbarian et al. (36), and Zargar et al. (37).

\section{Objectives}

Considering the high prevalence of body image disorders among Iranian primiparous women, also the role of body image satisfaction in increasing marital satisfaction (38) and couples compatibility (39), this research aimed to determine the effectiveness of cognitive behavioral therapy based on the Cash's eight-step model in primiparous women's body image.

\section{Materials and Methods}

This research was a pretest-posttest quasiexperimental study conducted on 73 primiparous women referring to health centers in Zahedan in 2015. The subjects were selected according to convenience sampling method and randomly assigned into intervention and control groups. The sample size was calculated based on the obtained results of a primary study. Living with the husband, non-existence of miscarriage or stillbirth, lack of diagnosed mental diseases, having no systemic diseases and delivery complications, non-occurrence of recent sorrowful event, age range of 20 - 40 years, being at least in the 3rd month of delivery, and being literate were the inclusion criteria. Being absent in more than two sessions, communicative problems, body deformation, amputation, burning scar or lesion as well as body mass index more than 30 (indicating obesity) formed the exclusion criteria.

Multidimensional body-self relations questionnaire (MBSRQ) that consisted of two parts of demographic and personal information in 46-items was used to collect data. MBSRQ is a self-assessment scale made by Cash (1997) to evaluate body image (40). There are six subscales in this instrument including appearance evaluation (AE), appearance orientation (AO), fitness evaluation (FE), fitness orientation (FO), subjective weight (SW), and body areas satisfaction (BAS). The subscale of appearance evaluation involves seven questions scoring 7-35. The appearance orientation subscale has twelve questions with minimum and maximum scores of 12 and 60, respectively. The subscale of fitness evaluation has three questions scoring 3 -15. The subscale of fitness orientation includes thirteen questions scoring 13 - 65. The subscale of Subjective Weight has two questions scoring $2-10$. The subscale of Body Areas Satisfaction consists of nine questions scoring 9 - 45. Some items are reverse-scored questions. The total score obtained by summing subscale scores is considered as total score of body image, scoring 46-230. The individuals are requested to mark their degree of agreement with each question on a five- point scale (completely disagree to completely agree). 
The responses score 1 - 5 based on the Likert scale. A higher score on MBSRQ indicates more body satisfaction (26).

Psychometric characteristics of this tool have been approved in many international studies such as those conducted by Annis et al. (15), King et al. (41), and Bekker et al. (42). Rahati (2004) carried out a research in Iran (43) and obtained a correlation ( 0.55$)$ between body image and selfesteem $(\mathrm{P}<0.001)$. Cronbach's alpha values of $0.85,0.60$, $0.76,0.46,0.79,0.80$, and 0.81 were obtained respectively for the total body image and subscales of AE, AO, FE, FO, SW, and BAS among 217 female subjects. On a sample of 67 individuals, the correlation coefficient between the scores of two tests during a two-week interval was calculated as 0.78 for appearance evaluation, 0.75 for appearance orientation, 0.71 for fitness evaluation, 0.69 for fitness orientation, 0.84 for subjective weight, and 0.89 for Body areas satisfaction, which all indicate appropriate test-retest reliability of the scale. In addition, Cronbach's alpha values of the total scale and its subscales in Raghibi and Minakhani research (44) were $0.74,0.74,0.80,0.76,0.66,0.78$, and 0.71 , respectively. In this research, the reliability was confirmed via Cronbach's alpha by giving the values of $0.88,0.80,0.91$, $0.84,0.79,0.90$, and 0.82 respectively.

In order to speed up the groups' formation and decreasing waiting time of subjects in the intervention group, the participants were initially allocated to the intervention group and after completing the group and reaching the quorum, they were assigned to the control group. It should be noted that due to the lack of tendency to continue the research or inaccessibility to participants because of their immigration or changing their residence, 12 participants were dropped in posttest stage and hence, the number of participants reduced to 61 (31 people in the intervention group and 30 in the control group). At the beginning, members of each group filled out the questionnaire and their weight was measured using SECA digital scale, made in Germany, in light clothes without any additional tool. Furthermore, the height of the subjects was measured using a stadiometer owned by the Health Center under the circumstances without footwear, with heels on the ground, three points of the body, heel, hip, and head back touching the stadiometer or the wall, the legs straight completely, and the arms laying beside the body. The intervention group, divided into the subgroups of six to twelve-member), received the cognitive behavioral body image therapy based on the Cash's eight-step model in six sessions of 60 to 90 minutes during three weeks (twice a week), while the control group remained pending and not receiving any training related to body image but regular cares. After six weeks, the posttest was carried out on both groups by completing the MBSRQ, measuring their weight, and calculating body mass index. Framework and content of cognitive behavioral therapy sessions (Table 1) were designed and executed based on Cash's eight-step model (2008). In the first session, teamwork package was distributed to the subjects and its summary on pamphlets was presented to the subjects to be reviewed.

Table 1. Framework and content of Cognitive Behavioral Therapy Sessions

\begin{tabular}{|c|c|}
\hline Session & Description \\
\hline 1st Session & $\begin{array}{l}\text { Introduction, definition of body image and the problems } \\
\text { arising from body dissatisfaction, group discussion about } \\
\text { appearance changes related to pregnancy, delivery, and } \\
\text { postpartum; body image self- assessment tests }\end{array}$ \\
\hline 2nd Session & $\begin{array}{l}\text { Recognizing negative body image roots in the past and } \\
\text { present; training mindful self-monitoring technique; } \\
\text { training body image ABCs; training to write daily diary of } \\
\text { body image; implementing mirror reflection technique }\end{array}$ \\
\hline 3rd Session & $\begin{array}{l}\text { Reviewing assignments; training mindfulness and } \\
\text { acceptance techniques; training systematic desensitization } \\
\text { technique; recognizing and correcting current hypothesis } \\
\text { related to the appearance; recognizing and correcting } \\
\text { cognitive distortions of appearance }\end{array}$ \\
\hline 4th Session & $\begin{array}{l}\text { Reviewing assignments; training, understanding, and } \\
\text { confronting with body image evasive actions such as } \\
\text { escaping and hiding; understanding, confronting, delaying, } \\
\text { and restricting obsession techniques of appearance; } \\
\text { technique of exposure and response prevention }\end{array}$ \\
\hline 5th Session & $\begin{array}{l}\text { Reviewing assignments; relaxation training; diaphragmatic } \\
\text { breathing and mental imagery; training to meet body's } \\
\text { rights; exercising positive and suitable physical activities; } \\
\text { training to enjoy time following improvement of fitness and } \\
\text { appearance and amplifying sentience }\end{array}$ \\
\hline 6th Session & $\begin{array}{l}\text { Reviewing assignments; training protective methods of } \\
\text { positive body image; confronting with people who disturb } \\
\text { the body image; examining the participants' progress; } \\
\text { continuing the use of skills acquired in training }\end{array}$ \\
\hline
\end{tabular}

The data were analyzed via IBM SPSS (Statistical Package for the Social Sciences) Software, version 20, on the results obtained from 61 participants (31 in the intervention group and 30 in the control group). First, we used Shapiro-Wilk Test to assure that the data obtained on the variables have a normal distribution; therefore, the condition of parametric tests is available. The entire comparisons were done between two domains at $\mathrm{P}$ value $<$ 0.05 as significance level. To describe the sample, descriptive statistics including mean and standard deviation were used and to compare dependent variables in both intervention and control groups, independent T-test was used. We applied Levene's Test to assess the homogeneity of variances of dependent variables calculated in both intervention and control groups as presuppositions in order to use Analysis of covariance (ANCOVA) test. This test was used to evaluate the effectiveness of cognitive behavioral therapy in body image (total score) and its constructs. Also, the effects of some intervening variables including age, weight in posttest stage, body mass index in posttest stage, educa- 
tion level, delivery type, ethnicity, breastfeeding condition, and intentional or unintentional pregnancy and pretest scores were considered.

\section{Results}

Participants with minimum age of 20 and maximum of 33 appeared in the intervention group whose mean and standard deviation were $25.64 \pm 3.18$, while in control group, minimum age of 20 and maximum of 34 with mean and standard deviation of $25.23 \pm 3.97$ were obtained. The results of independent T-test showed that there was no statistically significant difference between two groups in terms of age $(\mathrm{P}=0.681)$.

Moreover, minimum, maximum, and mean values of weight were $37.50,87.00$, and $59.00 \pm 10.72 \mathrm{~kg}$, respectively, in the intervention group and 42.30, 85.20, and $60.22 \pm$ $10.12 \mathrm{~kg}$, respectively, in the control group. According to the results obtained from independent T-test, there was no statistically significant difference between two groups in terms of weight $(\mathrm{P}=0.649)$. In the intervention group, the mean height was $158.19 \pm 8.23 \mathrm{~cm}$, which was in the range of 142.00 to $177.00 \mathrm{~cm}$, while in the control group the mean height was $159.15 \pm 6.63 \mathrm{~cm}$ in the range of 146.00 to $173.00 \mathrm{~cm}$. The results obtained from independent Ttest showed that there was no statistically significant difference between two groups in terms of height $(\mathrm{P}=0.620)$. Minimum and maximum values of body mass index in the intervention group were 16.89 and 29.87 , respectively, with mean of $23.74 \pm 3.39$; these values were not significantly different from those of control group according to the results of independent T-test $(\mathrm{P}=0.878)$.

In addition, Chi-square test showed that there was also no significant difference between two groups of intervention and control in terms of education level $(P=0.7)$, breastfeeding status $(P=0.1)$, ethnicity $(P=0.4)$, intentional or unintentional pregnancy $(\mathrm{P}=0.1)$, and delivery type $(\mathrm{P}=0.6)$.

Independent T-test showed the scores of body image $(P=0.7)$, appearance evaluation $(P=0.7)$, appearance orientation ( $P=0.5)$, fitness evaluation $(P=0.8)$, fitness orientation $(\mathrm{P}=0.8)$, subjective weight $(\mathrm{P}=0.4)$, and body areas satisfaction $(\mathrm{P}=0.5)$ were not significantly different between two groups in the pretest stage. In the posttest stage, however, there was a statistically significant difference in the subscale of appearance evaluation $(\mathrm{P}=0.016)$. Table 2 presents mean and standard deviation of scores on wholebody image and its constructs (in MBSRQ) in both intervention and control groups in pretest and posttest stages.

Considering age, posttest weight, posttest body mass index, education level, breastfeeding status, delivery type, intentional pregnancy, and ethnicity variables as covariate and controlling the pretest scores, the results of analysis of covariance (ANCOVA) for each variable showed that in the posttest, mean score of appearance evaluation ( $\mathrm{P}=0.0001)$, mean score of body areas satisfaction $(\mathrm{P}=0.0001)$, and mean score of body image $(\mathrm{P}=0.0001)$ in the intervention group were significantly higher than the corresponding scores in the control group. It means that the cognitive behavioral body image therapy resulted in the change of variables among the participants of the intervention group. The results of analysis of covariance related to the effectiveness of intervention in body image scores have been summarized in Table 3.

However, there was no significant difference between intervention and control groups in the mean of appearance orientation $(P=0.4)$, fitness evaluation $(P=0.5)$, fitness orientation $(P=0.2)$, and subjective weight $(P=0.3)$ in the posttest stage via analysis of covariance test.

\section{Discussion}

This research was conducted to evaluate the effect of group cognitive behavioral therapy on body image of primiparous women who referred to health centers in Zahedan city in 2015. The obtained results demonstrated that group cognitive behavioral therapy based on Cash's eightstep model is a suitable method to improve total body image and some of its aspects among primiparous women. The findings of this study are in agreement with the results obtained in previous studies focusing on the effect of cognitive behavioral therapy on other groups, including the effectiveness of cognitive behavioral therapy in negative body image $(23,24,29)$, body image of women under mastectomy (25), and body image of Iranian girl students (26) in addition to studies dealing with the effectiveness of cognitive behavioral therapy in those who are suffering from body dysmorphic disorder $(32,34,37)$, persons with binge eating disorder $(33,35)$, and burnt women (36). No exclusive study has been carried out using Cash's cognitive behavioral therapy on primiparous women's body image, although there are much evidence on vulnerability of body image in this group of women (8-14) and psychiatric problems associated with as well $(8,9)$.

Cognitive behavioral interventions may result a reduction in the individuals' attention to the difference between their real and ideal appearance that is one of the most important reasons for body image disorders (45). This intervention also helps individuals control thoughts and feelings about their appearance; this method of therapy pays attention to promoting self-efficacy (36). In fact, cognitive reconstruction makes individuals to challenge the validity of opinions and beliefs about their appearance, reevaluate them, and even introduce logic doubts, and substitute 
Table 2. Mean and Standard Deviation of Scores on Whole-Body Image and its Constructs in Both Intervention and Control Groups in Pre- and Post-Intervention Stages ${ }^{\mathrm{a}}$

\begin{tabular}{|c|c|c|c|c|}
\hline \multirow[t]{2}{*}{ Group Variable } & \multicolumn{2}{|c|}{ Intervention Group } & \multicolumn{2}{|c|}{ Control Group } \\
\hline & Pre-Intervention & Post-Intervention & Pre-Intervention & Post-Intervention \\
\hline Appearance evaluation & $22.61 \pm 5.33$ & $24.83 \pm 4.43$ & $23.10 \pm 5.31$ & $21.08 \pm 5.15$ \\
\hline Appearance orientation & $47.54 \pm 6.07$ & $49.93 \pm 5.77$ & $46.60 \pm 6.40$ & $49.90 \pm 6.28$ \\
\hline Fitness evaluation & $10.51 \pm 2.77$ & $10.06 \pm 2.59$ & $10.66 \pm 2.60$ & $10.53 \pm 2.83$ \\
\hline Fitness orientation & $42.64 \pm 8.96$ & $41.74 \pm 8.40$ & $43.06 \pm 9.20$ & $41.46 \pm 8.48$ \\
\hline Subjective weight & $5.87 \pm 2.39$ & $6.12 \pm 2.20$ & $6.33 \pm 2.27$ & $6.16 \pm 2.24$ \\
\hline Body areas satisfaction & $30.29 \pm 6.07$ & $33.45 \pm 5.39$ & $31.26 \pm 5.83$ & $31.33 \pm 5.12$ \\
\hline Body image & $159.48 \pm 23.14$ & $166.16 \pm 20.81$ & $161.03 \pm 22.56$ & $159.20 \pm 22.39$ \\
\hline
\end{tabular}

${ }^{\mathrm{a}}$ Values are expressed as mean $\pm \mathrm{SD}$.

Table 3. Results of Analysis of Covariance on the Effectiveness of Cognitive Behavioral Therapy in Primiparous Women's Body Image Upon Control of Pretest Scores and Some Demographic Variables

\begin{tabular}{|c|c|c|c|c|c|c|c|}
\hline Origin of Changes & Total Squares & Degree of Freedom & Mean Squares & $\mathbf{F}$ & PValue & Degree of Effectiveness & Test Power \\
\hline Age & 89.553 & 1 & 89.553 & 1.290 & 0.261 & 0.025 & 0.200 \\
\hline Delivery type & 34.719 & 1 & 34.719 & 0.500 & 0.483 & 0.010 & 0.107 \\
\hline Education level & 196.746 & 1 & 196.746 & 2.438 & 0.099 & 0.054 & 0.379 \\
\hline Breastfeeding status & 53.240 & 1 & 53.240 & 0.767 & 0.85 & 0.015 & 0.138 \\
\hline Intentional pregnancy & 1.289 & 1 & 1.289 & 0.019 & 0.892 & 0.000 & 0.052 \\
\hline Posttest Body mass index & 91.514 & 1 & 91.514 & 1.318 & 0.256 & 0.026 & 0.203 \\
\hline Posttest weight & 174.568 & 1 & 174.568 & 2.515 & 0.119 & 0.048 & 0.343 \\
\hline Pretest & 16727.639 & 1 & 16727.639 & 240.961 & 0.000 & 0.828 & 1.000 \\
\hline Group & 984.291 & 1 & 984.291 & 14.179 & 0.000 & 0.221 & 0.589 \\
\hline Error & 3471.030 & 50 & 69.421 & & & & \\
\hline Total & 1643777.000 & 61 & & & & & \\
\hline
\end{tabular}

those opinions and beliefs that are central core for negative automatic thoughts in specific situations by doxastic beliefs. This matter can help improve the individual's body image remarkably. The Cash's model emphasizes on recognizing and correcting appearance-related presumptions and cognitive distortions. Similarly, some essential training have been introduced into this model along with confronting with measures such as escaping from special situations, disguising weakness and imperfections, eliminating preoccupation with an imagined defect in appearance through, for example, repetitive behavior applying make-up and obsess over the appearance, that may result in improving body image.

Besides, this model emphasizes training systematic desensitization skills through the mirror, exposure and response prevention, learning how to spend pleasure times through positive and pleasant activities on behavioral issues as the most important element of body image (1).

In addition to total body image, six subscales evaluating a specific aspect of body image were studied in this research. According to analysis of covariance, two subscales of appearance evaluation and body areas satisfaction were affected by cognitive behavioral therapy. the significant effect of this training on appearance evaluation may be related to the emphasis of the model on privacy dialogs of the individuals about their appearance, discovering activators, beliefs and consequences chain ( $\mathrm{ABC}$ Chain) through measures such as mindful self-monitoring and confronting with them after destructive presumptions and cognitive distortions were introduced and corrected.

Also, the effectiveness of training in body areas satisfac- 
tion was proved. relative body dissatisfaction in mothers (with parts of body) after delivery may be related to hair loss during breastfeeding, dark skin patches of pregnancy such as chloasma, telangiectasia, varicose veins, stretch marks on the areas of the body (such as breasts, abdomen, and thighs), and sagging breasts and abdomen tissues among some of women. In Cash's therapy model, mother lists the important areas of her body that she is dissatisfied with in sequence and then, she is faced with them by applying desensitization techniques through mirror and exposure and response prevention (1).

However, this research did not find any evidence indicating the effectiveness of cognitive behavioral therapy based on cash's eight-step model in the aspects of body image including appearance orientation, fitness evaluation, fitness orientation, and subjective weight. The deficiency of the therapy in this regard may be restricted to several issues including short-term training, insufficient period to do assignments and exercises for first-time mothers busy with caring their newborns, post-partum stress, having no chance to exercise for living with other family members, and lack of privacy among some participants. Selecting mothers with normal body mass index and ignoring obese mothers are some specific reasons for inefficient treatment on subjective weight construct. Besides, Cash's cognitive behavioral model focuses on body image as whole and does not emphasize on any particular aspect (26). Rayegan et al. (26) reported that total body image increased in subscales of appearance evaluation and fitness orientation and find no significant difference in appearance orientation, fitness evaluation, subjective weight, and body areas satisfaction constructs.

The results of a meta-analytic review carried out by Alleva et al. (46) pointed out that all types of interventions used, whether cognitive behavioral therapy or not, has a low but reliable effect on body image, demonstrating the difficulty of changing this structure in people. Consequently, we have to express the lack of serious damage to primiparous women's body image studied in this research compared to other groups who are suffering from body image disorders or pathology. This is because the value of parenting among some social and cultural groups in this region of Iran is more highlighted than body changes occurred following pregnancy and this matter is not psychologically considered by mothers as a disorder.

\subsection{Conclusions}

The results confirmed the effectiveness of cognitive behavioral therapy based on cash's eight-step model in body image and several considerable body image constructs such as appearance evaluation and body areas satisfaction among primiparous women. We can use this appropriate treatment in a simple way, for example, in the form of selfstudy booklet in order to improve the problems associated with body image among different groups of mothers. However, it is advised to include such treatments in postpartum health care schedule. Maternal positive mental image of body will result in promoting their mental health, creating more effective interactions with newborn, improving infant cares, enhancing degree of satisfaction and quality of their marital relationships, and finally experiencing a more pleasant parenting.

\subsection{Limitations}

Because of specific ethnicity, religious and social conditions of women in the area of the study, we should be precautious to generalize the results. Furthermore, no followup was performed to evaluate the efficiency of intervention. Conducting the study only on primiparous women and selecting a relatively small size of sample are the other limitations.

The present research was confirmed by the research ethics committee of vice chancellor office of research and technology affiliated to Zahedan University of Medical Sciences in Iran by coding IR.ZAUMS.REC.1394.168. Here, acquiring oral consent, ensuring privacy and confidentiality of health services information, not explaining name and personal details and objectives of the research, describing the intervention and manual as well as allowing the subjects to leave the research whenever they desired, were the most significant ethical considerations.

\section{Acknowledgments}

This research was extracted from a MA Thesis carried out under financial support of Zahedan University of Medical Sciences. Hereby, we would like to express our special thanks of gratitude to colleagues and especially all mothers who helped us a lot finalize this project.

\section{Footnotes}

Authors' Contribution: Ali Navidian, Zahra Moudi and Mehri Esmaealzade conceived and designed the study. Mehri Esmaealzade collected the clinical data. Ali Navidian and Zahra Moudi interpreted the clinical data and performed the statistical analysis. Mehri Esmaealzade drafted the manuscript. Ali Navidian and Zahra Moudi revised the manuscript critically for important intellectual content. All authors red and approved the final manuscript.

Conflict of Interests: The authors declare that they have no competing interests.

Funding/Support: There is no Funding. 


\section{References}

1. Cash TF. The body image workbook: An 8-step program for learning to like your looks. New Harbinger Publications, Inc; 1997.

2. Thompson JK. Body image disturbance: Assessment and treatment Pergamon Press; 1990.

3. Jarry JL, Ip K. The effectiveness of stand-alone cognitive-behavioural therapy for body image: a meta-analysis. Body Image. 2005;2(4):31731. doi: 10.1016/j.bodyim.2005.10.001. [PubMed:18089198].

4. Jarry JL, Berardi K. Characteristics and effectiveness of stand-alone body image treatments: a review of the empirical literature. Body Image. 2004;1(4):319-33. doi: 10.1016/j.bodyim.2004.10.005. [PubMed: 18089164].

5. Meland E, Haugland S, Breidablik HJ. Body image and perceived health in adolescence. Health Educ Res. 2007;22(3):342-50. doi: 10.1093/her/cylo85. [PubMed: 16957015].

6. Garrusi B, Nematallahee VR, Etminan A. The relationship of body image with depression and self-esteem in pregnant women.J Health Dev. 2013;2(2):117-27.

7. Boscaglia N, Skouteris H, Wertheim EH. Changes in body image satisfaction during pregnancy: a comparison of high exercising and low exercising women. Aust N Z J Obstet Gynaecol. 2003;43(1):41-5. [PubMed: 12755346].

8. Welsh AC. A biopsychosocial model of body image in new mothers. University of Maryland; 2009.

9. Gjerdingen D, Fontaine P, Crow S, McGovern P, Center B, Miner M. Predictors of mothers' postpartum body dissatisfaction. Women Health. 2009;49(6):491-504. doi: 10.1080/03630240903423998. [PubMed: 20013517]

10. Hodgkinson EL, Smith DM, Wittkowski A. Women's experiences of their pregnancy and postpartum body image: a systematic review and meta-synthesis. BMC Pregnancy Childbirth. 2014;14:330. doi: 10.1186/1471-2393-14-330. [PubMed: 25248649].

11. Lombardo JM. A multidimensional assessment of body image experiences during pregnancy and postpartum. University of Hartford; 2001.

12. Patel P, Lee J, Wheatcroft R, Barnes J, Stein A. Concerns about body shape and weight in the postpartum period and their relation to women's self-identification. J Reprod Infant Psychol. 2005;23(4):34764.

13. Pauls RN, Occhino JA, Dryfhout V, Karram MM. Effects of pregnancy on pelvic floor dysfunction and body image; a prospective study. Int Urogynecol J Pelvic Floor Dysfunct. 2008;19(11):1495-501. doi: 10.1007/s00192008-0670-3. [PubMed: 18566731].

14. Rallis S, Skouteris H, Wertheim EH, Paxton SJ. Predictors of body image during the first year postpartum:a prospective study. Women Health. 2007;45(1):87-104. doi:10.1300/J013v45n01_06. [PubMed: 17613464].

15. Annis NM, Cash TF, Hrabosky JI. Body image and psychosocial differences among stable average weight, currently overweight, and formerly overweight women: the role of stigmatizing experiences. Body Image. 2004;1(2):155-67. doi: 10.1016/j.bodyim.2003.12.001. [PubMed: 18089148].

16. Hausenblas HA, Fallon EA. Exercise and body image: A meta-analysis. Psychol Health. 2006;21(1):33-47.

17. Von Soest T, Kvalem IL, Roald HE, Skolleborg KC. The effects of cosmetic surgery on body image, self-esteem, and psychological problems. J Plastic Reconstruct Aesth Surg. 2009;62(10):1238-44.

18. Muller-Pinget S, Carrard I, Ybarra J, Golay A. Dance therapy improves self-body image among obese patients. Patient Educ Couns 2012;89(3):525-8. doi: 10.1016/j.pec.2012.07.008. [PubMed: 23031613].

19. Carvalho-Ferreira JP, Cipullo MA, Caranti DA, Masquio DC, AndradeSilva SG, Pisani LP, et al. Interdisciplinary lifestyle therapy improves binge eating symptoms and body image dissatisfaction in Brazilian obese adults. Trends Psychiatry Psychother. 2012;34(4):223-33. [PubMed: 25923071].
20. Parizadeh H, Hassanabadi H, Mash hadi A, Taghizade KA. Investigating Effectiveness of Existential and Reality Group-Therapy in Treatment of Body-Image Problem in Women Who Undergo Mastectomy [in Persian]. Iran J Obstet Gynecol Infertil. 2012;15(22):27-35.

21. Nicolino JC, Martz DM, Curtin L. Evaluation of a cognitive-behavioral therapy intervention to improve body image and decrease dieting in college women. Eat Behav. 2001;2(4):353-62. [PubMed: 15001028].

22. Hofmann SG, Asnaani A, Vonk IJ, Sawyer AT, Fang A. The Efficacy of Cognitive Behavioral Therapy: A Review of Meta-analyses. Cognit Ther Res. 2012;36(5):427-40. doi: 10.1007/s10608-012-9476-1. [PubMed: 23459093].

23. Rosen JC, Saltzberg E, Srebnik D. Cognitive behavior therapy for negative body image. Behav Ther. 1989;20(3):393-404.

24. Rosen JC, Orosan P, Reiter J. Cognitive behavior therapy for negative body image in obese women. Behav Ther. 1996;26(1):25-42.

25. Fadaei S, Janighorban M, Mehrabi T, Ahmadi SA, Mokaryan F, Gukizade A. Effects of cognitive behavioral counseling on body Image following mastectomy. J Res Med Sci. 2011;16(8).

26. Rayegan N, Shaeeiri MR, Asghari MMA. The investigation of cognitivebehavioral therapy influence based on Cash's eight stage model on negative body image of female college students [in Persian]. Daneshvar Raftar. 2006;19.

27. Butters JW, Cash TF. Cognitive-behavioral treatment of women's body-image dissatisfaction. J Consult Clin Psychol. 1987;55(6):889-97. [PubMed: 2891736].

28. Grant JR, Cash TF. Cognitive-behavioral body image therapy: Comparative efficacy of group and modest-contact treatments. Behav Ther. 1996;26(1):69-84.

29. Strachan MD, Cash TF. Self-help for a negative body image: A comparison of components of a cognitive-behavioral program. Behav Ther. 2002;33(2):235-51.

30. Hutchinson MG. Transforming body image: Your body, friend or foe? Curr Feminist Issues Psychother. 1982(3):59.

31. Dworkin SH, Kerr BA. Comparison of interventions for women experiencing body image problems. J Counsel Psychol. 1987;34(2):136.

32. Phillips KA, Rogers J. Cognitive-behavioral therapy for youth with body dysmorphic disorder: current status and future directions. Child Adolesc Psychiatr Clin N Am. 2011;20(2):287-304. doi: 10.1016/j.chc.2011.01.004. [PubMed: 21440856].

33. Hilbert A. Cognitive-behavioral therapy for binge eating disorder in adolescents: study protocol for a randomized controlled trial. Trials. 2013;14:312. doi: 10.1186/1745-6215-14-312. [PubMed: 24066704].

34. Wilhelm S, Buhlmann U, Hayward LC, Greenberg JL, Dimaite R. A cognitive-behavioral treatment approach for body dysmorphic disorder. Cogn Behav Pract. 2010;17(3):241-7.

35. Azari S, Poursharifi H, Fata L. Efficacy of short term cognitivebehavioral therapy on binge eating disorder. Int $J$ Behav Sci. 2012;6(4):377-82.

36. Rahbarian M, Tarkhan M, Jalali M. The effectiveness of cognitivebehavioral group therapy on self-concept and body image in burnt women [in Persian]. J Qazvin Univ Med Sci. 2012;15(4):45-52.

37. Zargar Y, Sayad S, Bassak Nejad S. The effectiveness of cognitivebehavioral group therapy on reducing body dysmorphic disorder and interpersonal sensitivity among female high school students. $J$ Res Behav Sci. 2012;9(5).

38. Meltzer AL, McNulty JK. Body image and marital satisfaction: evidence for the mediating role of sexual frequency and sexual satisfaction. J Fam Psychol. 2010;24(2):156-64. doi: 10.1037/a0019063. [PubMed: 20438191].

39. Mickelson KD, Joseph JA. Postpartum body satisfaction and intimacy in first-time parents. Sex Roles. 2012;67(5-6):300-10.

40. Ray A. The Psychologist's Book of Personality Tests. J Allied Health. 2002;31(1):51.

41. King TK, Matacin M, Marcus BH, Bock BC, Tripolone J. Body image evaluations in women smokers. Addict Behav. 2000;25(4):613-8. [PubMed: 10972454]. 
42. Bekker MHJ, Croon MA, Vermaas S. Inner body and outward appearance-the relationship between orientation toward outward appearance, body awareness and symptom perception. Pers Individ Differ. 2002;33(2):213-25.

43. Rahati A. Study of physical development and its relationship with self-esteem by comparing age groups, teenagers, middle-aged and elderly. Shahed university; 2007.

44. Raghibi M, Minakhany G. Body Management and its Relation with Body Image and Self Concept [in Persian]. Knowledge Res Appl Psychol.
2011;12(4):72-81.

45. Garrusi B, Garousi S, Baneshi MR. Body image and body change: predictive factors in an Iranian population. Int JPrev Med. 2013;4(8):9408. [PubMed: 24049621].

46. Alleva JM, Sheeran P, Webb TL, Martijn C, Miles E. A Meta-Analytic Review of Stand-Alone Interventions to Improve Body Image. PLoS One. 2015;10(9):e0139177. doi: 10.1371/journal.pone.0139177. [PubMed: 26418470]. 